increased. MRI showed atrophy and cystic changes in the left hemisphere with compensatory dilatation of the lateral ventricle. Thalidomide $(300 \mathrm{mg} /$ day $)$ was added to a midazolam iv drip, and partial seizure control was sustained. For the past 3 years, her seizures have been less intense and less frequent and have not interfered with everyday activities. Treatment includes thalidomide $5 \mathrm{mg} / \mathrm{kg}$, valproate $30 \mathrm{mg} / \mathrm{kg}$, clonazepam and piracetam. Apart from occasional leukopenia, no other adverse effects are reported. (Marjanovic BD, Stojanov LM, Zdravkovic DS et al. Rasmusen syndrome and long-term response to thalidomide. Pediatr Neurol Aug 2003;29:151-156). (Respond: Dr Marjanovic, Department of Neurology, Pediatric Clinic of Mother and Child Health Care Institute, Belgrade, Yugoslavia).

COMMENT. Thalidomide may be considered as an alternative treatment for refractory and incapacitating seizures in Rasmussen syndrome, when more conventional therapies have failed. One previous report found thalidomide effective in a 7-year-old male with Rasmussen syndrome whose seizures were associated with high levels of CSF tumor necrosis factor a. (Ravenscroft A et al. Brain Dev 1998;20:398). The antiepileptic effect may be related to inhibition of the tumor necrosis factor and boosting of the immune response. Apart from the high teratogenicity, a sensory neuropathy is the major adverse complication of thalidomide therapy.

\title{
LEVETIRACETAM IN LANDAU-KLEFFNER SYNDROME
}

A 5-year-old girl with seizures and progressive language deterioration and a diagnosis of Landau-Kleffner syndrome was benefited by treatment with levetiracetam at Johns Hopkins Hospital, Baltimore, MD. Video-EEG monitoring showed continuous 2- to 3-Hz spike-wave discharges, maximal left, during sleep. Carbamazepine and valproate were tapered, and levetiracetam $500 \mathrm{mg}$ twice daily $(50 \mathrm{mg} / \mathrm{kg} /$ day $)$ substituted. Seizures were controlled, the EEG at 12-month follow-up showed only focal left temporofrontal spikes, and language skills slowly improved. (Kossof EH, Boatman D, Freeman JM. Landau-Kleffner syndrome responsive to levetiracetam. Epilepsy Behav Oct 2003;4:571575). (Respond: Dr Eric H Kossof, Department of Neurology, The Johns Hopkins Hospital, Jefferson 128, 600 North Wolfe St, Baltimore, MD 21287).

COMMENT. Psychotic behavior reported as an adverse reaction to levetiracetam needs to be weighed against possible benefits of treatment of LKS and other childhood epilepsies (Kossof EH et al. Epilepsia 2001;42:1611-1613).

The risk factors and incidence of behavioral abnormalities severe enough to require discontinuation of levetiracetam were determined in a study of 553 patients treated at the University of Minnesota, Minneapolis. (White JR et al. Neurology November 11, 2003;61:1218-1221). Thirty-eight patients $(6.9 \%)$ discontinued levetiracetam because of behavioral abnormalities. Risk factors for this adverse reaction included a faster titration rate to maximal dose, history of a psychiatric disorder, and symptomatic generalized epilepsy. Slower titration to optimal dose levels is advised in patients at risk of behavioral or psychotic effects.

Phenacemide (Phenurone), a broad spectrum anticonvulsant, introduced in 1949, and effective in the control of complex partial (psychomotor) seizures, is particularly prone 
to cause behavioral side effects (Tyler MW, King EQ. JAMA 1951;147:17-21). The severity of psychosis is directly related to the control of seizures. Personality changes, aggressive behavior, paranoid and depressive reactions, and acute psychosis were reported in $17 \%$ of patients treated. The use of phenacemide was largely discontinued because of the risk of mortalities from aplastic anemia and hepatitis. Coker SB and colleagues resurrected phenacemide for therapy of complex partial seizures in 13 children at Loyola University and Christ Hospital, Chicago, IL (Neurology 1987;37:1861-1866). Twelve responded, 9 were seizure-free for 2-12 months, one had a behavior and personality disorder, and one developed nausea and vomiting necessitating drug withdrawal. (see Progress in Pediatric Neurology I, PNB Publ, 1991;pp77-78).

"Paradoxical normalization" in childhood epilepsy (acute psychiatric symptoms with abrupt cessation of seizures and normalized EEG) was particularly common during trials of phenacemide in the 1950's, but this phenomenon is also reported concomitant with the control of Lennox-Gastaut syndrome and other seizures by ACTH therapy (Amir N, Gross-Tsur V. Epilepsia 1994;35:1060-1064; see Progress in Pediatric Neurology III, 1997;pp71-73). One patient, aged 9, became seizure free within 7 days of initiating ACTH. His behavior changed, he became disoriented, aggressive, hyperactive, dyspraxic, and dysphasic, and he required psychiatric hospitalization. He gradually improved over 5 years. In 2 patients with paradoxical normalization, seizures recurred when ACTH and vigabatrin were discontinued, and the psychiatric symptoms resolved. Discontinuance of the offending anticonvulsant and recurrence of seizures are usually followed by normalization of behavior.

\section{VASCULAR AND TRAUMATIC DISORDERS}

\section{BRAIN INJURY WITH SICKLE CELL DISEASE}

The relationship between brain injury and vasculopathy in 146. sickle cell (SCD) patients with hemoglobin SS, the most serious form of SCD, was evaluated by MRI and MRA at St Jude Children's Research Hospital, Memphis, TN. At an average age of 10 years, $46 \%$ of patients had brain injury revealed by MRI in the form of cystic infarction, ischemic damage, encephalomalacia, or atrophy, and $64 \%$ had vasculopathy identified by MRA as arterial totuosity (limited vasculopathy), and stenosis or occlusion (extensive vasculopathy). Patients with abnormal MRA usually had abnormal MRI, and only $28 \%$ had normal neuroimaging and angiography. Vasculopathy is prodromal to brain injury with $\mathrm{SCD}$; it was limited in patients with cystic infarction and extensive with encephalomalacia. Large arteries were affected in $31 \%$ of patients with brain injury and small arteries in $69 \%$. The degree of brain injury with SCD is related to the degree of vasculopathy. (Steen RG, Xiong X, Langston JW, Helton KJ. Brain injury in children with sickle cell disease: prevalence and etiology. Ann Neurol November 2003;54:564-572). (Respond: Dr R Grant Steen, Department of Psychiatry, University of North Carolina at Chapel Hill, Campus Box 7160, Chapel Hill, NC 27514).

COMMENT. Brain injury is a common complication of sickle cell disease with hemoglobin SS, and the severity of injury is correlated with the degree of vasculopathy. Patients with normal vasculature have normal MRI and MRA, those with mild 